\title{
A CASE OF MUSICOGENIC EPILEPSY
}

\author{
BY \\ DAVID SHAW \\ Sutton Emergency Hospital \\ and \\ DENIS HILL \\ Teaching and Research Laboratory, Maudsley Hospital, London \\ (RECEIVED 13TH DeCEMBER, 1946)
}

DefINITE and unequivocal examples of musicogenic epilepsy (epilepsy induced by musical sounds) are clinical rarities. In the most comprehensive review, Macdonald Critchley (1937) described eleven cases personally known to him and referred to a further nine culled from the literature. Some of the latter were by no means established, since only short anecdotal accounts were given of them. The onset of symptoms was noted as occurring later than is usual in idiopathic epilepsy. Further, many of the patients displayed an unusual knowledge and a keen appreciation of classical music. The musical stimulus might be of a specific kind, but the nature of the epileptic phenomena varied considerably; in some only minor attacks were induced, and in others only major attacks. The importance of the emotional state was stressed by Critchley, particularly in the period between first hearing the music and the onset of the attack. Speculations about the pathogenesis of this unusual form of epilepsy were made. It was accepted from the evidence and description of these cases that hysteria is no explanation, and an opinion was expressed that a conditioned reflex to certain musical sounds may be present. Critchley in 1942 briefly reported two further cases. In one an emotional disturbance set up by classical music was closely related to the actual seizure, and in the second -it was only certain notes or tones that induced an epileptiform fit. In this latter case there was a history of closed head injury nine years previously. Taylor (1942) reported a further case, in which a head injury occurred six years before the occurrence of occasional epileptiform attacks. These attacks bore a close relation to music, and finally both major and minor attacks were readily induced by it.
Case Report

The patient, a married woman of 44 , of German origin, came to this country when Hitler's succession to power in 1932 seemed imminent. She comes of a middle-class family in Saxony. Her sister is reported to have died of "fits" as a child. The patient developed normally and did very well at school, which she left at the age of 15 . She then did clerical work, and later became a secretary to a large German Film Company and travelled widely. She was cosmopolitan in outlook, and politically strongly democratic and hence bitterly opposed to the rapidly growing Nazi philosophy. In England she worked regularly as a secretary until just after the outbreak of the war. In 1935 she had a liaison with a married man, who died suddenly, and after she heard the news she had an amnesic and confused episode lasting several hours, during which she wandered aimlessly around the streets. She married some four years ago, her husband serving for much of this time in the Army overseas. She is happy with her husband, who is very considerate and sympathetic. Her menses are normal and regular. She had an appendicectomy eleven years ago. There is no history of any convulsions in early life, but she had a nervous breakdown in 1929. At this time she was depressed, but recovered after a rest in the country. There is no history of head injury. She is ordinarily vivacious and energetic, prides herself on her efficiency, and is sociable and very popular, artistic, and sensitive to " atmosphere." She seeks her own way and is rather argumentative. She is very keen on good music, which at any time will move her very much, and is herself a moderately good pianist.

In February, 1941, she had a period of automatism while speaking on the telephone. She had no recollection of events during the attack and, in fact, put through the call again five or ten minutes later and repeated her message. Similar momentary " blank attacks" recurred on the average of one every two or three weeks. They occurred at any time, although much more frequently during the day. On two or three occasions she was 
incontinent of urine. Her memory, previously very good, became unreliable; embarrassing mistakes and difficulties in connexion with her secretarial work occurred, and she herself gave up the job. The "blanks" continued. She became depressed, sleepless, and worried by the situation in which she found herself. She was treated with small doses of phenobarbitone and psychotherapy, but with no relief to her symptoms. She obtained night work as a packer in a food factory, since her "blanks" were much less frequent at night. In a communication to her friend and subsequent employer, she complained at this time about her bad memory and grumbled about the incessant radio programmes at the factory where she worked. In April, 1943, she was sent for a period of convalescence at the Lady Chichester Hospital, Hove. There the connexion with music first became apparent. A typical attack occurred when she was in the hospital Chapel listening to the organ. Dr. F. Reitman observed that music induced " a dreamy state lasting about five minutes, followed by a severe generalized headache." Two major attacks were induced by music. They commenced with conjugate deviation of the eyes and a turning of the body to the right ; tonic and clonic phases followed, and, after a brief period of unconsciousness, a transient confused state. Corneal reflexes were present but bilateral extensor responses were noted.

At this time the EEG was done on two occasions by Dr. Cobb at Haywards Heath E.M.S. Hospital. On the first occasion the report was as follows :

" Resting : Low voltage record consisting of about equal proportions of 2 rhythms $-11 \mathrm{c} / \mathrm{sec}$. and about $20 \mathrm{c} / \mathrm{sec}$. up to 25 microvolts. In addition there are many slower waves, single and in short bursts at about $6 \mathrm{c} / \mathrm{sec}$. of about the same voltage. On overbreathing ( 3 minutes) there is a slight increase in the number and amplitude of the slow waves, persisting for some time."

Sedatives were discontinued and she "enjoyed" music, and after fourteen days a major attack occurred. A second EEG was done and reported on as follows :

" Dominant rhythm at $12 \mathrm{c} / \mathrm{sec}$, rather irregular and not very persistent, voltage up to 50 microvolts and blocked by eye opening. There were other rhythms present. (1) Continuous $20 \mathrm{c} / \mathrm{sec}$. rhythm, mostly of low voltage, but occasionally comparable with that of dominant rhythm. (2) Much 4-6 c/sec. at about same amplitude as dominant rhythm. (3) One short burst of high voltage $3 \mathrm{c} / \mathrm{sec}$. waves. On overbreathing (3 minutes) there was a great increase in slow activity persisting for a considerable time and including several short bursts of high voltage $3 \mathrm{c} / \mathrm{sec}$. wave and spike complexes."

The conclusion was that the response to overbreathing was now quite typically epileptic.

She was transferred to Sutton E.M.S. Hospital for further investigation in August, 1943, coming under the care of one of us (D.S.). Physical examination showed her to be a well-nourished, heavily-built woman. Blood pressure was $110 / 70 \mathrm{~mm} \cdot / \mathrm{Hg}$. No-significant abnormality was elicited in the central nervous or other systems. Cerebrospinal fluid pressure was $240 \mathrm{~mm}$. C.S.F. and the
Queckenstedt test was qualitatively normal. The Wassermann reaction was negative in blood and cerebrospinal fluid. A radiograph of the skull showed no abnormality. During an EEG examination gramophone records were played (a Tosca aria and a noisy jazz record). The patient became tearful and emotional, but no attack was induced, nor was any change noted in her EEG. Two brief petit-mal attacks were observed while she was in hospital. They were not related to music. She left hospital after a month and continued to attend the Maudsley Hospital as an out patient. She managed to carry on in a secretarial job as an employee of a former acquaintance and fellow-countryman, but both minor and major turns persisted and were now becoming more easily " fired off" by musical stimuli. They occurred by day and by night, and in the case of the latter were often connected with a dream about music. Life was now becoming very difficult for the patient. She avoided music, as she said, "like the plague," and the situation had reached absurd lengths. If they went out together her husband would make a preliminary reconnaissance to find a café without a wireless or gramophone, and even the street musicians near her place of work were bribed by her employer to keep away from the vicinity. She had been treated during this period as an out patient with Caps. "epanutin," gr. $1 \frac{1}{2}$ b.d. and later t.d.s., and Tab. phenobarbitone, gr. 1 daily, without any demonstrable effect on the frequency of the seizures. During this period she put on nearly 3 stone in weight, reaching 1.5 stone, and was treated with $\mathrm{Tab}$. thyroideum siccum ge $1 \frac{1}{2}$ b.d.

She was readmitted to Sutton E.M.S. Hospital of Jan. 28, 1946. She was now voluble and rather moro tearful and emotionally unstable than formerly. Alway co-operative, she would nevertheless quickly get put ouf and become irritable. She demanded that all allowances be made for her susceptibility to music. There was no evidence of a general intellectual deterioration, but tests showed an impairment of retentive memory: She was intensely self-centred. Firstly she worried over her failing memory and the consequent difficulties at work, and secondly, her German origin-which she did her best to hide-was a source of considerable distress to her. She was afraid of being considered a Nazi sympathizer in view of her Aryan descent. On the other hand, she expressed fears that Nazi organizations in London would force her to join their ranks under the threat of harming her relatives in Germany. The fate of her parents was causing her considerable anxiety. During the height of the 1940-1941 blitz on London she had been at first fortified by music. She had made a practice of putting on her radio as loud as possible to drown the noise of the air-raids. But it now seemed to her that music was "distorted" in some way and invariably induced unpleasānt emotions.

Minor attacks were now almost invariably induced by music. In these she suddenly felt " dead," and regained $\frac{D}{O}$ consciousness feeling drowsy and muddled for about half-an-hour. These attacks were frequently followed $\mathrm{N}$ by a period of automatism lasting from twenty minutes to an hour, and in these episodes, of which she had no 


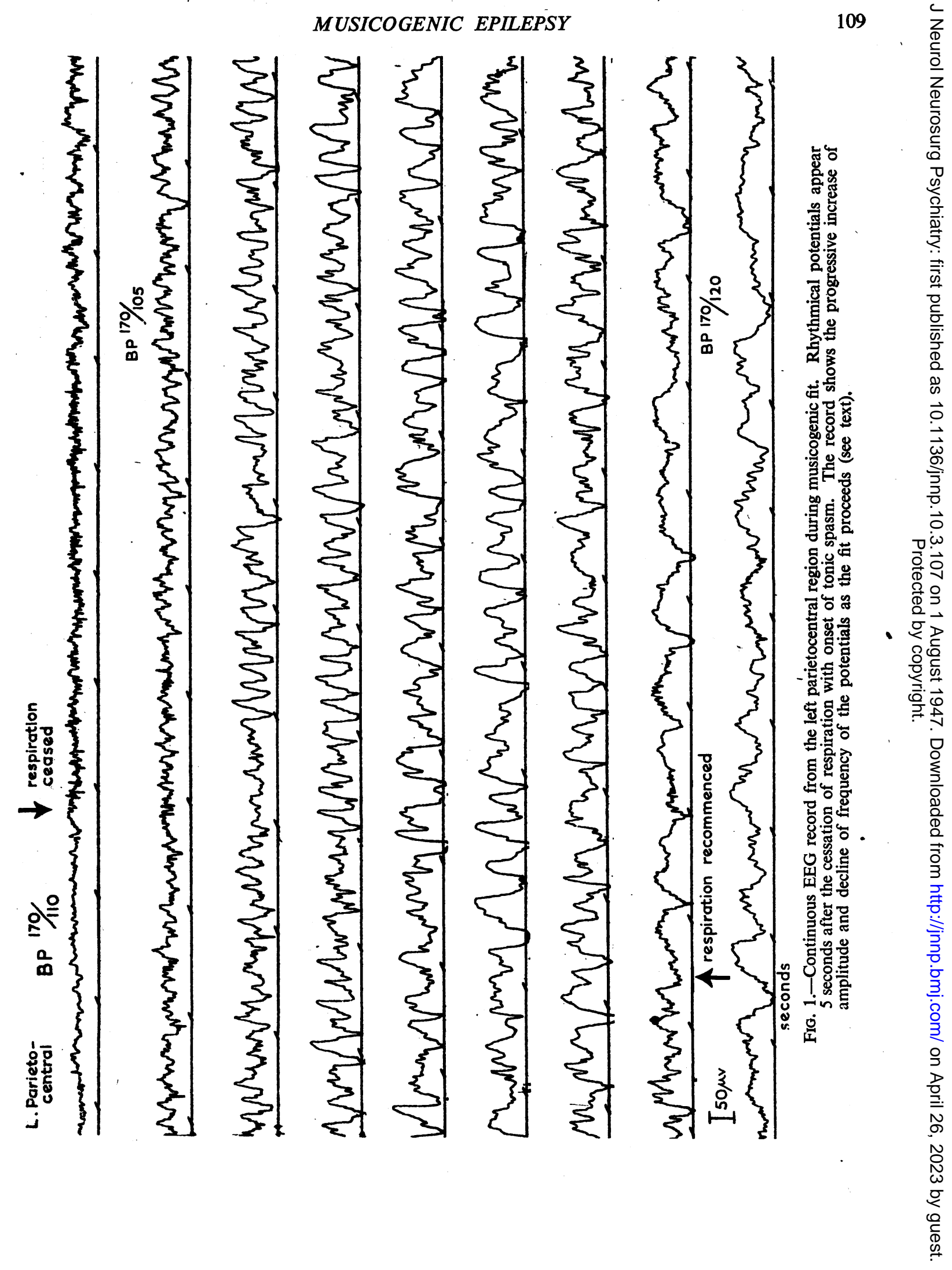


recollection, she was reported to have pulled back the blackout curtains on one occasion, and on another to have wandered off from her office in a dazed state. She stated she had even done some shopping or eaten her meal in her usual café with no memory at all of having done so. Characteristically, there was no warning of the attacks, which averaged three or four a month.

The major attacks occurred less frequently, one in every two or three months, and were also usually induced by music, but not invariably. They occurred both by night and by day, without aura. She had bitten her tongue and micturated during the attacks on several occasions.

Again no significant abnormality in the central nervous system was elicited on clinical examination, but the blood pressure was now $160 / 110 \mathrm{~mm} . / \mathrm{Hg}$. The urine was normal. On lumbar puncture the cerebrospinal fluid pressure was $200 \mathrm{~mm}$. C.S.F., and the C.S.F. was qualitatively normal. Radiographs of the skull showed no bony abnormality, and when further radiographs were taken following air replacement by the cisternal route by Mr. McKissock, no distortion of the ventricular system was found. Later, following the injection of an opaque substance into both carotid arteries, $x$-ray pictures of the head revealed a normal vascular appearance. Aural investigations by Miss E. Whetnall revealed no abnormality in the ears. The hearing tested by the audiogram was normal, and no subjective or objective response occurred to any tones except to $512 \mathrm{c} / \mathrm{min}$., which, when varied in intensity and interrupted, was unpleasant to the patient. She became emotional but no fit ensued. She was similarly irritated by the Barany noise box. When the patient watched a revolving drum the direction of which was reversed, the optokinetic nystagmus obtained to the left side was greater than that obtained to the right. This finding suggested a central lesion on the left side.

Attacks Deliberately Induced by Music.-Throughout her stay in hospital no spontaneous seizures occurred, but attacks were successfully induced by music on each of the nine occasions attempted. Various kinds of -music, from a musical comedy song to a Wagnerian Overture, have all produced varying degrees of emotional agitation and tearfulness followed by a fit. The pattern of the fit was repeated on subsequent occasions and the vesical incontinence occurred twice.

On hearing music she became agitated immediately, and talked rapidly, repeating . various inconsequential comments in an effort apparently to distract her attention. She seemed to talk for the sake of talking. After ten minutes her right hand began to make pawing movements -which widened in range. Then head and shoulders flexed, and her right hand slowly went up to her nose which she gripped firmly. She stiffened in a tonic spasm, pursed her lips markedly, held her breath and became cyanotic, staring ahead with fixed congested eyes. This phase lasted altogether from two to three minutes. No abnormal neurological signs were elicited. She then got up from her chair, fumbled about in a confused way, muttering and evidently looking for her handbag. Contact was gradually re-established in spite of the continuing music. She complained of headache and asked repeatedly how she had managed to get into the room. There was no recollection for any of the conversation during the period just before the fit.

A series of electro-encephalographic investigations were carried out at the Maudsley Hospital. With the patient lying at rest, records were taken with a Grass 3 channel apparatus. Bipolar leads were used. The alpha rhythm was of low voltage, irregular in form and varied in frequency from $10-13 \mathrm{c} / \mathrm{sec}$; the distribution was symmetrical, the rhythm being seen best in the lower part of the hemispheres with antero-posteriorly placed bipolar leads, but better still with transverse electrode positions. Blocking to visual stimuli was normal. Continuous medium voltage fast activity at $20-22 \mathrm{c} / \mathrm{sec}$. was seen in the fronto-central regions. With all transverse electrode placements irregular moderate voltage (50-70 $\mu \mathrm{v}$.) bilaterally synchronous rhythmic potentials were seen. Among these, three rhythms could be identified having slightly different amplitudes, viz., (1) $3 \mathrm{c} / \mathrm{sec}$. at 60-70 $\mu \mathrm{v}$.- irregular complex wave forms in bursts of 2-3 waves, coming chiefly from the post central areas; (2) 5-6 c/sec. potentials at 40-50 $\mu \mathrm{v}$. having relatively sinusoidal appearance in the lower central areas (theta rhythm), and (3) $4 \mathrm{c} / \mathrm{sec}$. potentials at $50-60 \mu \mathrm{v}$. rather irregular in form, tending to lateralize to the left side in the anterior temporal region. No focal location for the potentials of this discharge could, however, be obtained with any constancy.

The EEG was then recorded while music was played.o No significant change in the rhythms was seen before the onset of the fit. During this phase, which lasted frong three to five minutes, signs of emotion, however, wer⿳亠口冋 evident. The onset of the fit on each of four occasions was heralded by an abrupt cessation of respiration coincident with tonic, generalized muscular contractiog which was evident in the EEG record as fast irregulap of activity, conducted probably from neck muscles. The. muscle contraction was not sufficient to result in sigo nificant change of posture, although slight flexion of the head and trunk was evident on one occasion. During the initial few seconds automatic rotatory movements of the right arm were noticed, with pouting of the pursed lips. Six to eight seconds after the cessation of breathing, low voltage $(30-40 \mu \mathrm{v}$.) $6-7 \mathrm{c} / \mathrm{sec}$. potentials appeared synchronously and with equal amplitude on the two hemispheres. During the succeeding 72-112 seconds, until respiration recommenced, the potentials showed a steadily progressive increase of amplitude, with progressive decline in frequency, and finally developed a rhythmical high voltage $\left(150 \mu \mathrm{v}\right.$.) $2 \frac{1}{2}-3 \mathrm{c} / \mathrm{sec}$. bilaterally synchronous discharge. When respiration was reestablished, this discharge lost its rhythmical sinusoidal appearance, the waves becoming irregular in outline, slower (1-2 c/sec.), and of lower voltage (Fig. 1). A gradual return to consciousness was now evident, the patient behaving in a dazed manner for which there was subsequent amnesia. This period lasted variously from ten to twenty minutes.

While music was played the patient showed overt signs of emotion. Fig. 2 is a record of the respiratory excursions, recorded on the drum of a Sandborn B.M.R. N apparatus from -which the lime had been removed. Fig. 3 demonstrates the changes of heart rate during the 


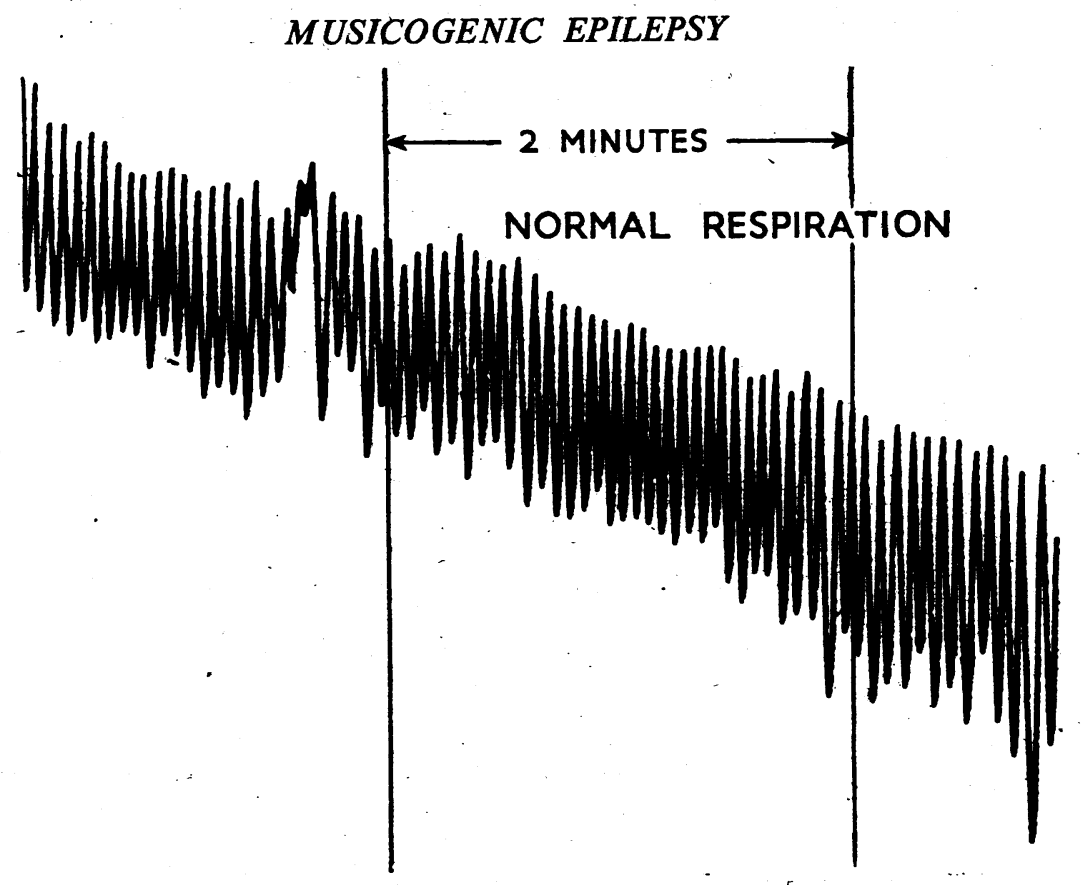

RESPIRATION DURING MUSIC

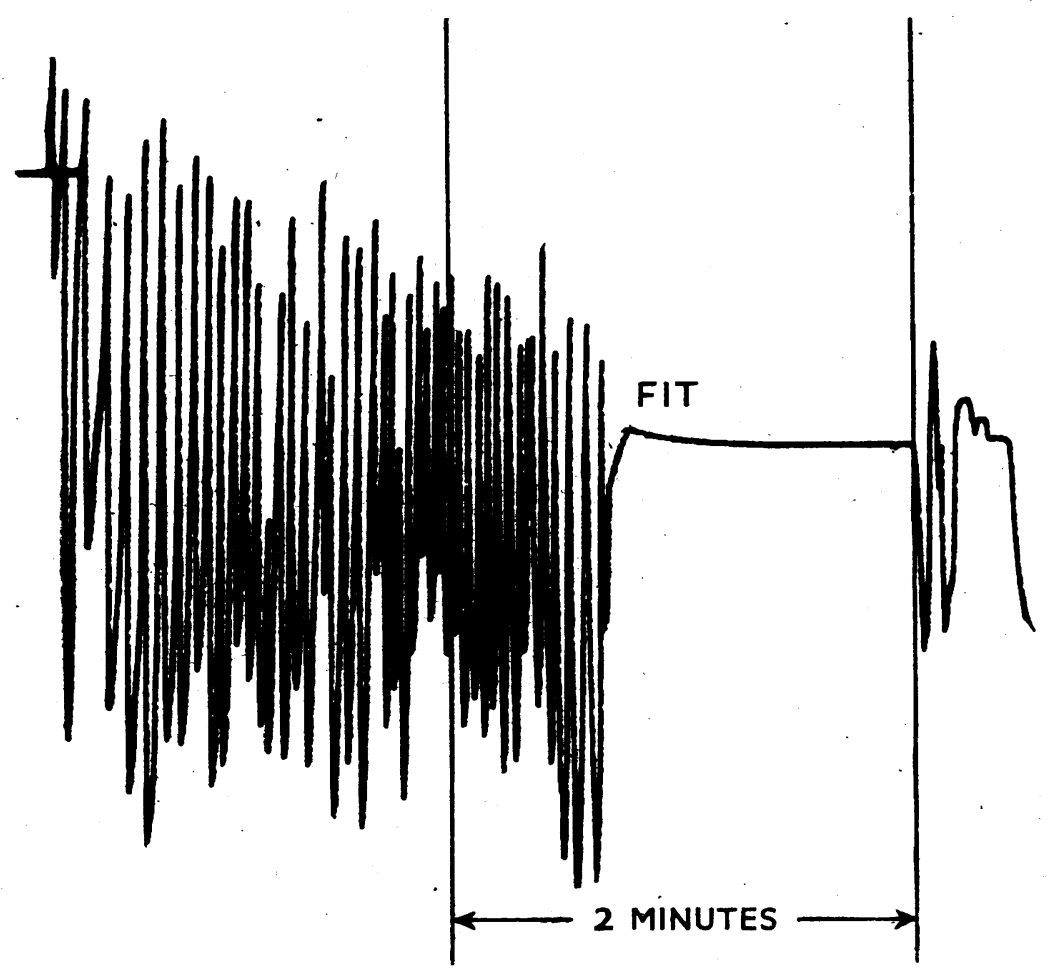

Fig. 2.-Record of the respiratory excursions recorded on the drum of a Sandborn B.M.R. apparatus from which the lime had been removed. 


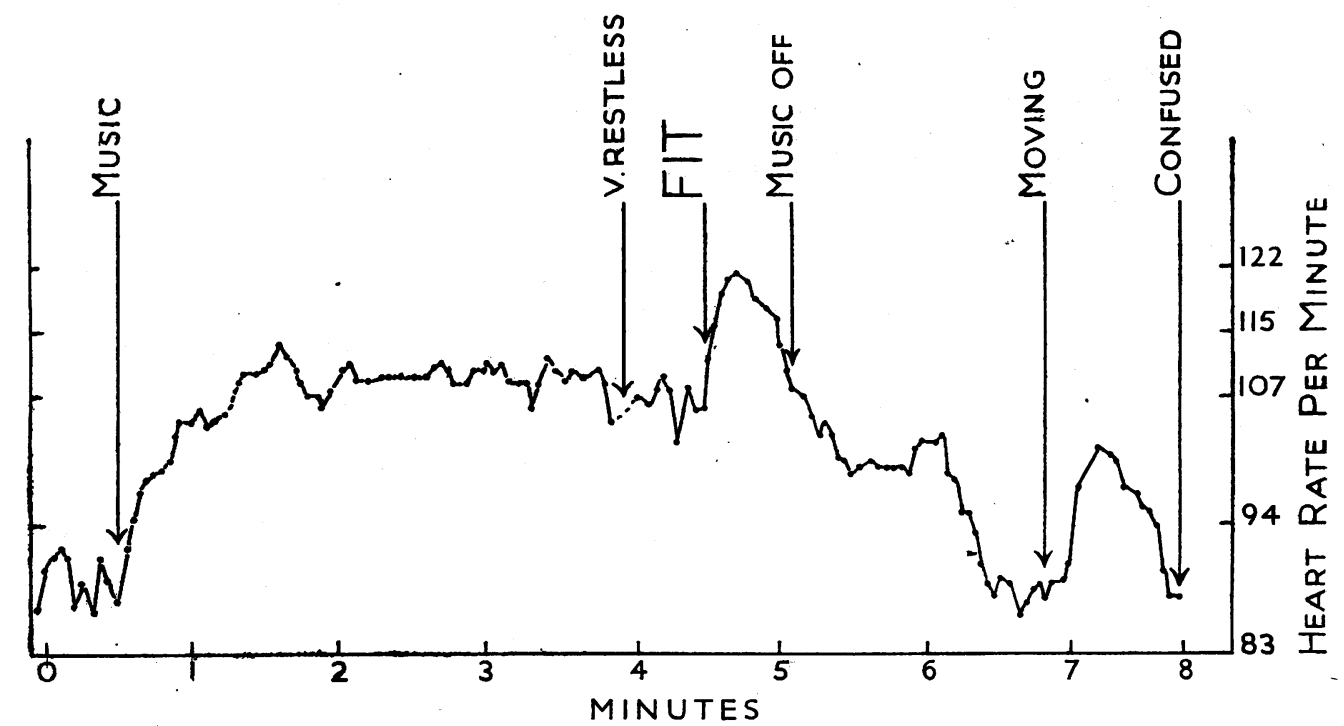

Fig. 3.-Shows changes in heart rate during the pre-fit period of musical stimulation.

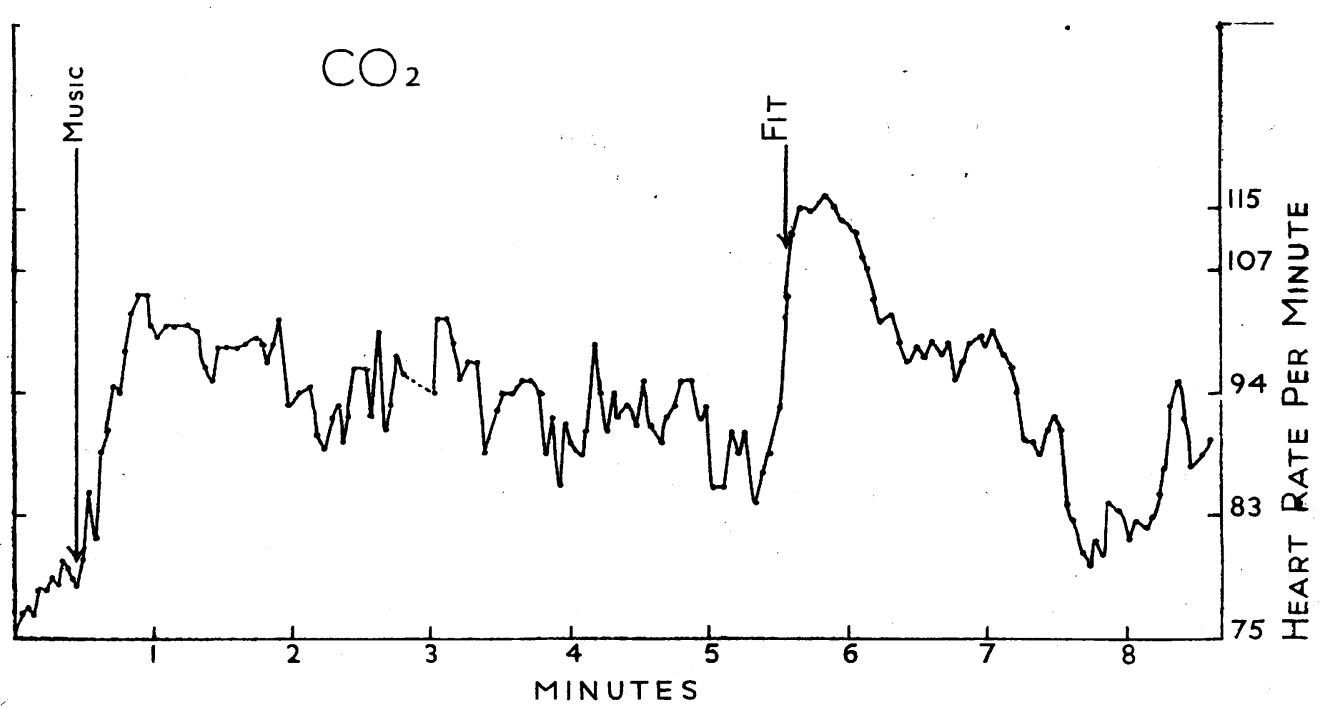

Fig. 4. - Similar record of the heart rate changes during a period of musical stimulation, while the patient breathed oxygen containing 5 per cent. carbon dioxide. 

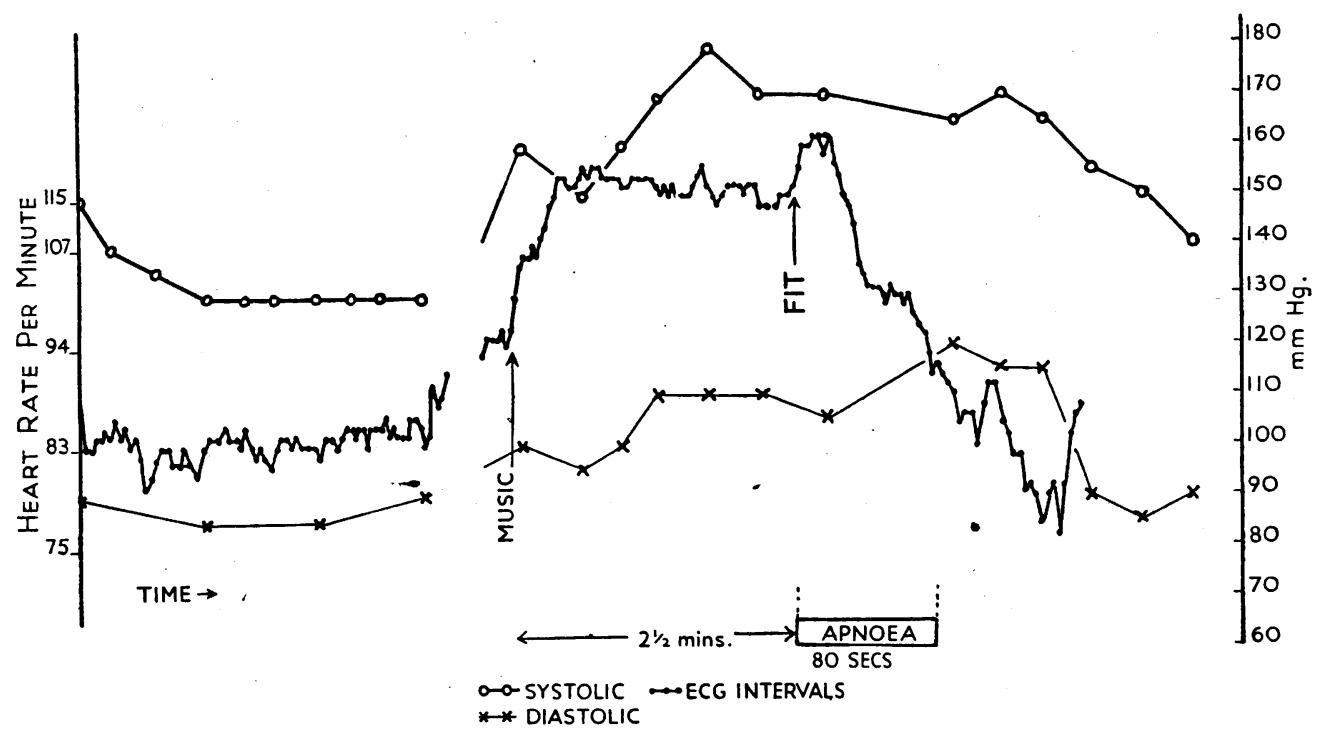

Fig. 5.-Composite record of the heart rate and blood-pressure changes (taken by sphygmomanometer from the arm) during a further investigation.
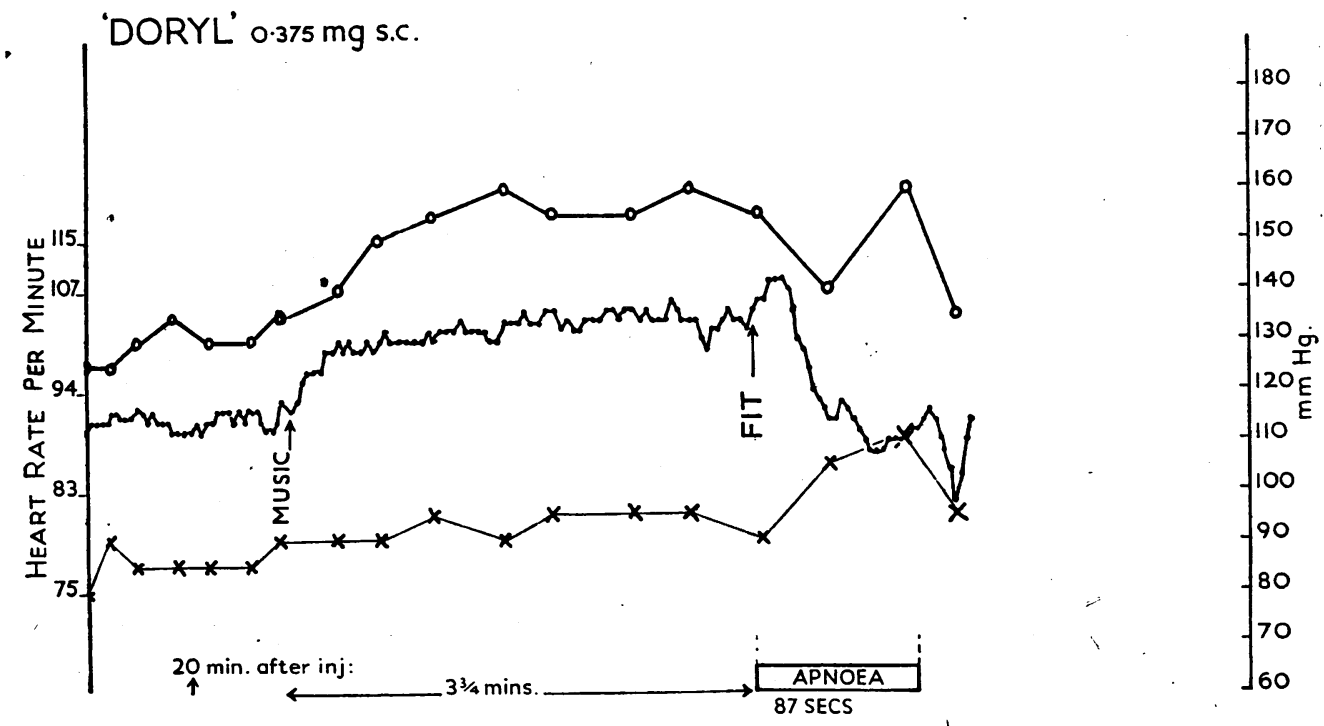

Fig. 6.-Heart rate and blood-pressure changes after injection of $1 \mathrm{c.cm}$. of " doryl " intravenously. 


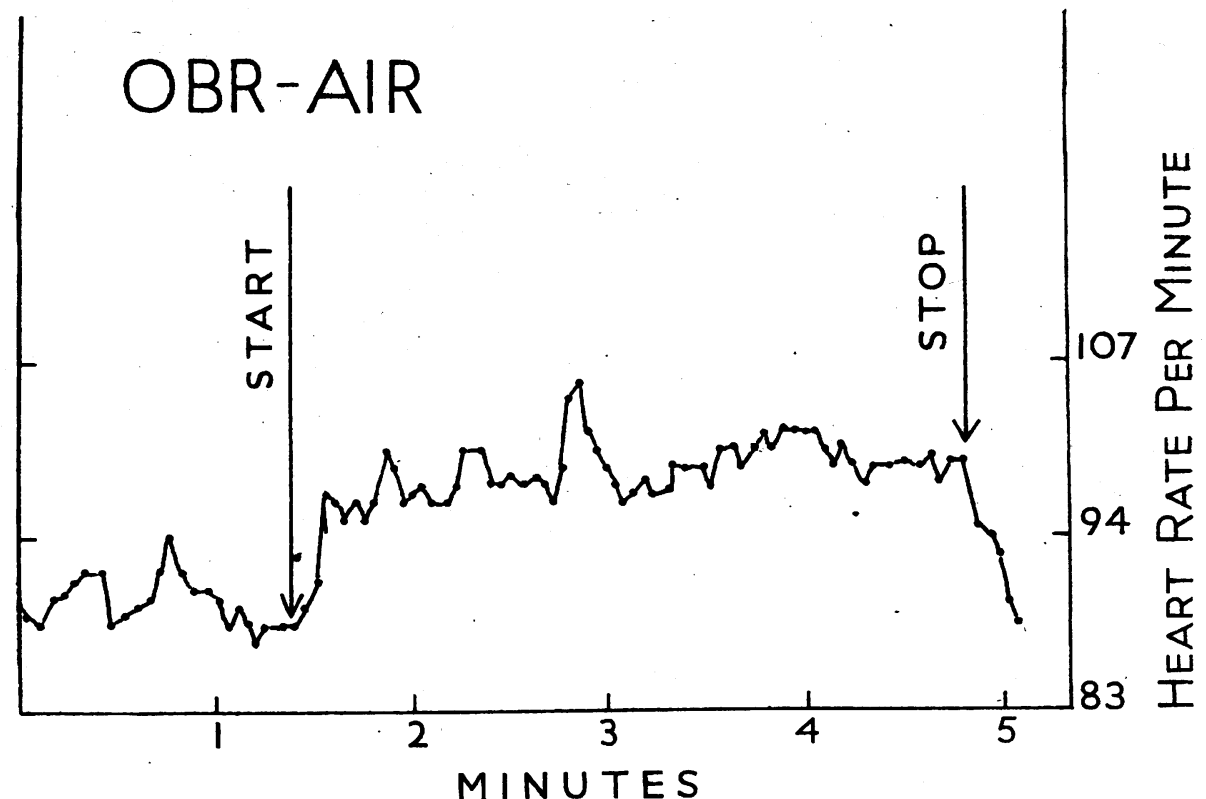

Fig. 7.-Record of the heart rate taken during a period of three minutes' voluntary overbreathing.

pre-fit period of musical stimulation. This was obtained by recording the arm-to-arm electrocardiogram on one channel of the Grass equipment (the other two channels recording the EEG). With a constant paper speed, variations in the distance between five successive $R$-waves of the electrocardiogram, measured in millimetres, give an accurate account of the heart rate. Fig. 4 is a similar record of the heart-rate changes during a period of music stimulation, while the patient breathed oxygen containing 5 per cent. carbon dioxide. Fig. 5 is a composite record of the heart-rate and blood-pressure changes (taken by sphygmomanometer from the arm) during a further investigation. Fig. 7 is a record of the heart rate taken during a period of three minutes' voluntary overbreathing. These investigations demonstrate increased depth and frequency of respiration, significant increase of heart rate, and a rise in systolic and diastolic blood pressure while music was played. A further increase of heart rate and blood pressure is observed at the onset of the fit. Fig. 4 illustrates that breathing 5 per cent. carbon dioxide facilitated the increase of heart rate and did not prevent the subsequent fit. In this case, therefore, the mechanism of fit precipitation was not alkalosis from overbreathing. It should also be recorded that voluntary overbreathing of much greater depth for three minutes had not induced a fit, nor equivalent increase of heart rate.

In view of the increased heart rate, blood pressure, and respiration rate during the playing of music, it was decided to observe the effects of a drug having an acetylcholine-like action. "Doryl," 1 c.cm., was injected intramuscularly and the procedure repeated. This did not prevent the devetopment of a fit, but in the opinion of observers the objective signs of emotion were less evident while music was played. This observation gatis some support from the heart rate and blood-pressire changes, both of which were less on this occasin (Fig. 6).

\section{Discussion}

It seems clear that we are dealing with a case- $0 f^{2}$ epilepsy. For the following reasons the suggest that the musicogenic phenomena are a manifestation of hysteria can be disposed of, at any rate as far as this case is concerned. There is a family historys of epilepsy. Urinary incontinence has occurred if the attacks on several occasions, and the fit observed have frequently been followed by a periog of automatism. Major attacks have also been reliably witnessed and have been accompanied bo tongue-biting and urinary incontinence. Further the EEG examination made in 1943 showed the presence on overbreathing of the wave and spike complex discharge, and this would suggest af idiopathic ætiology. However, minor fits began at the age of 41 and at first bore no relation to musicAs Critchley observed in his cases, the time of onset in this patient was later than is usual in cases of idiopathic epilepsy. 'Like the cases reported, fulf neurological investigations have failed to demonstrate a lesion in our patient. However, the evidence suggests a local onset for the fit in this caseIn the deliberately induced fits it was repeatedis noticed that the moyement first began in Jacksonia 
fashion in the right hand and arm, with adversive turning of the head and eyes to the right. This suggests a focal epileptogenic area in the left hemisphere, probably the left temporal lobe. This is further. supported by the results of the optokinetic test, and to a certain extent by the EEG. But of the nature of the focus we have no knowledge. The air studies and arteriogram were normal.

Psychological examination showed that, although superficially well adjusted, the patient was neurotic. There is an earlier history of a nervous breakdown induced by stress, and she has shown a tendency to react explosively to emotional stimuli; 'she became amnesic and confused after hearing of her lover's sudden death. Was this an earlier manifestation of epilepsy? In general, the musical stimulus is of a non-specific kind, although it is true that a pure tone of $512 \mathrm{c} / \mathrm{min}$. when varied produced an emotional response, but no fit. Fits are induced by any kind of music, seemingly. The patient has always been keenly appreciative of music (perhaps over-emotional to it), and only latterly has found that musical sounds are distorted and produce an unpleasant emotional response. Critchley has discussed two different views of the pathogenesis of musicogenic epilepsy-the physiogenic and the psychogenic. In the first it is supposed that music itself induces the fit by causing increased cerebral blood flow. Records taken of the heart rate and blood pressure during the stimulation period and also throughout the fit show that there is a marked adrenaline-like response commencing immediately the stimulation is given and continuing throughout the initial stages of the seizure. It has also been suggested that the hearing of music might induce overbreathing and thus precipitate a fit by alkalosis in a latent epileptic. Records of respiration do indeed show overbreathing, and of the type commonly associated with emotion, that is, of greater depth and increased frequency, and with irregularity of both depth and frequency. However, voluntary overbreathing for three minutes produced less increase of the heart rate than when listening to music at rest, and no fit was ever produced by this procedure. Further, when the patient breathed 5 per cent. carbon dioxide while listening to music a fit supervened in the usual way. The possibility that alkalosis from overbreathing is the cause of the fit in this case can, therefore, be excluded.

The heart rate and blood-pressure changes are of particular interest in a case of musicogenic epilepsy because of the association of such changes with audiogenic fits in rats (Lindsley and others, 1942).
The signs of emotion, restlessness, lacrimation, and overbreathing were invariably observed in this patient when she listened to music, and this association has been emphasized in other cases (Critchley, 1937). On the four occasions when records were made, similar heart rate and EEG changes were observed, indicating a temporal sequence of events. When the musical stimulus was given, and sometimes during the brief anticipatory period preceding $i$, a sharp rise in heart rate and systolic blood pressure occurred. After thirty or forty seconds the heart rate and blood pressure ceased to increase and remained steady, the normal variations of heart rate being less evident.

The type of EEG discharge during the fit is that commonly seen in epileptic psychomotor seizures (Gibbs and others, 1936; Jasper, 1941) and the initial frequency of the discharge, together with its bilaterally synchronous occurrence, is in favour of a basal origin for the cerebral dysfunction (Jasper, 1941 ; Cobb, 1944 ; Walter and Dovey, 1944). The progressive facilitation of the discharge indicates a focal origin, recruiting progressively more and more neurone groups.

It is relevant to consider the similarities and differences which this case shows with the audiogenic fits in rats investigated by many workers (Maier, 1939 ; Morgan and Morgan, 1939 ; Maier and Glaser, 1940 ; Lindsley and others, 1942). In certain strains of rats, though not carried as a simple mendelian dominant, a susceptibility to abnormal behaviour culminating in convulsions is found as a response to high-pitched sounds (whistle, keyjingling, etc.). The abnormal behaviour in response to sound stimuli shows two phases, bearing resemblance to the case reported here. In the first phase, seen as violent, undirected running and jumping ending in tonic-clonic convulsions, there are marked changes in heart rate and blood pressure, usually an adrenaline-like effect (Lindsley and others, 1942). The second phase is one of inactivity, the animal being comatose, showing no response to sensory stimulation. The reflexes and righting responses are absent and the animal can be moulded into various positions. There is a gradual return to normal. During this phase the heart rate falls sharply and then gradually returns to normal. Lindsley and others (1942) found that, if their rats were restrained, no fits occurred. In the unrestrained rats, the heart rate usually showed a sharp increase of rate of considerable magnitude and usually a decrease just before the attack. In other cases there was an initial fall in the heart rate. In our patient increase in the heart rate was invariable. The temporal sequence of events in the audiogenic 
seizure is emphasized by these writers. This consists of (1) increase of heart rate, (2) a marked electrocortical discharge in the EEG at the onset of the attack. In the present case the EEG characters are clearly different from those in the rats, though it is doubtful whether the two may be compared. In the rat the discharge-slow waves and mixed spikes and waves-is maximal at the onset of the fit and does not show the progressive build-up evident in our patient.

Lindsley and others (1942) found that physical restraint prevented the occurrence of seizures in their rats. Partial curarization had a similar effect. Following vagotomy the seizures were alşo prevented and no heart-rate changes occurred to sound stimuli. Since in the present patient the heart rate and blood pressure preceding the fit invariably showed an adrenaline-like response, an attempt to balance this with a drug having an acetylcholine-like action was made. Doryl injected intramuscularly resulted in less heart rate and blood-pressure change to music, and the overt signs of emotion-as judged by observers-were less during the stimulation phase, but the fit was not prevented. If the result of this experiment is considered significant, it may be regarded as evidence that the peripheral or cerebral vascular effects of emotional over-activity are not of major importance in the production of fits in this patient.

The earlier workers on audiogenic seizures in rats had likened the phenomena to the "experimental neurosis." Maier (1939) induced fits by a conflict situation in which the rats were forced to respond to, a physical stimulus which they had previously been conditioned to avoid. Maier and Glaser (1940) found that " barriers to response" to stimuli increased the frequency and susceptibility to fits. On the other hand, Lindsley and others (1942) prevented fits by restraining their rats. In the rats who were not restrained but who did not develop fits during auditory stimulation, some form of "substitute behaviour" was noticed, such as nose or ear rubbing and teeth chattering. It was observed that our patient would talk rapidly and become agitated when music was played. She would repeat various inconsequential comments in an effort apparently to distract her attention. However, she could not prevent the fit by these means. It has been noted already that Critchley (1937) considered the possibility that a conditioned reflex to musical sounds might have been created in these cases. In our patient's case, fits, both major and minor, had occurred before any relation to musical stimuli became apparent, and the evidence suggests that she is an idiopathic epileptic. The relationship to musical precipitation started during the London blitz, when no doubt emotional stress was associated with hearing music. After this the $\mathbb{Q}$ association with fit precipitation became progressively more complete. In the case of the rats, Lindsley and others (1942) conclude from their data that auditory stimulation rather than conflict $D$ neurotic reaction is the chief component in the production of seizures, and these workers suggest $\frac{}{\overline{2}}$ that the auditory stimulus excites autonomic centres in the diencephalon by direct spread. In the particular case reported here, there is much to $\overline{\bar{s}}$ suggest a conditioned process. Such a conditioned reflex cannot, however, be explained as a simple $\frac{\bar{\sigma}}{\sigma}$ pattern involving the acoustic nuclei and the dien- $\overline{\bar{\omega}}$ cephalon. Masserman (1943) in an extensive $\widehat{\Phi}$ review of his own and others' experiments, concludes oे that the hypothalamus behaves not as an afferent ${ }^{\circ}$ experience-mediating organ, but as a way-station $\vec{\circ}$

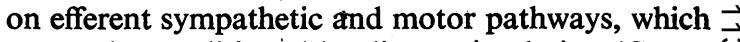
cannot be conditioned by direct stimulation (Gantt, $\stackrel{\omega}{\sigma}$ 1937; Gantt and Loucks, 1938). Attempts to condition "hypothalamic responses" to sound stimuli in lightly etherized animals failed, and such $\vec{\circ}$ attempts left no change in the action potentials $\omega$ from the hypothalamus. The establishment of $\vec{a} \vec{\circ}$ conditioned response is dependent upon the "meaning" value of the stimulus, and from this may be inferred that the function of the cerebral cortex is involved. This is supported by the fact that no fits could be produced by exposing the patient to pure tones, although she showed signs $\stackrel{0}{\rightarrow}$ of emotion with 512. The dependence on harmone $\overrightarrow{0}$ sounds would suggest a cortical receptor level and $₫$ the difference between "music" and pure tones for experience is one largely of " meaning." The fit pattern, the optokinetic responses, and the resting EEG pattern all suggest an epileptogenic zone in the left temporal lobe. The fits bear resemblance to the "dreamy states" seen in the temporal lobe epilepsy. However Beach and Weaver (1943) found that in the rat an intact cortex is not essential to the production of the fits. In fact, almost complete decortication increased the susceptibility to fits and the intensity and duration of them.

Although there are similarities in the temporal course of events between the epilepsy of this patient and the characteristic audiogenic seizures of rats, it would be unsafe to argue from the case of the latter as to site of origin of the epileptic discharge in the human. Against the clinical evidence indicating a focal discharge arising in the left temporal cortex is the evidence that no new pattern ? was observed in the EEG until six or eight seconds 
after the start of the fit, and the fact that when such changes appeared they were equal and synchronous on the two hemispheres. It is possible that the electrodes were placed too far away from the site of origin of the discharge, with the result that by the time it reached them the rhythm had developed bilateral synchrony. This is known to occur in temporal-lobe discharges (Jasper, 1941). On the other hand there is evidence (Walter and Dovey, 1944 ; Cobb, 1944) that rhythms with the frequency seen in their case, having bilateral synchrony, are found in lesions in the neighbourhood of the third ventricle. The extremely slow "build up" of the rhythms during the fit demonstrates that the discharge is progressing in the brain very slowly. It seems reasonable to suggest that the site of origin of the discharge in this patient is deep in the left temporal lobe, that it spreads predominantly towards the basal brain, and that it only involves the cortex at a later stage in the development of the fit.

\section{Summary}

1. The development of a specific musical stimulus to fit production is described in an epileptic woman.

2. Extensive clinical investigations failed to reveal an acquired cerebral lesion, although the fit pattern, optokinetic response, and inter-seizure EEG indicate an epileptogenic area in the left temporal lobe.

3. Increases of blood pressure, heart rate, and respiration while listening to music were observed in this patient. These were associated with overt signs of emotion.

4. Fits could not be induced by pure tones, although the patient felt emotional to a tone of 512 , which persisted and was varied in loudness. Different kinds of music were invariably followed by a fit within five minutes.

5. Electroencephalographic studies showed a constant pattern for the development of the fit. No change of rhythm was seen while music was played before the fit began. The cortical discharge began six or seven seconds after the clinical onset. This discharge consisted of $6 \mathrm{c} / \mathrm{sec}$. low voltage potentials having bilateral synchrony, steadily increasing in voltage and falling progressively in frequency to reach $2 \frac{1}{2}-3 \mathrm{c} / \mathrm{sec}$.

6. The possible mechanisms of fit production are discussed.

\section{REFERENCES}

Beach, F. A., and Weaver, T. (1943). J. comp. Neurol., $79,379$.

Cobb, W. A. (1944). J. Neurol., Neurosurg. Psychiat., 7,96.

Critchley, Macdonald, (1937). Brain, 60, 13. (1942). J. roy. Nav. Med. Serv., 28, 182.

Gantt, W. H. (1937). Amer.J. Physiol., 119, 313. and Loucks, R. B. (1938). Ibid., 123, 74.

Gibbs, F. A., Lennox, W. G., and Gibbs, E. L.'(1936). Arch. Neurol. Psychiat. Chicago, 36, 1225.

Jasper, H. H. (1941). In W. Penfield and T. C. Erickson : "Epilepsy and Cerebral Localization." Springfield. C. Thomas. p. 380.

Lindsley, D. B., Finger, F. W., and Henry, C. E. (1942). J. Neurophysiol., 5, 185.

Maier, N. R. F. (1939). " Studies of Abnormal Behaviour in the Rat." New York. Harper Bros. and Glaser, N. M. (1940). Comp. Psychol. Monogr.,? 16, 1.

Masserman, J. (1943). "Behaviour and Neurosis." Chicago. Univ. Press.

Morgan, C. T., and Morgan, J. D. (1939). J. Comp. Psychol., 27, 505.

Taylor, S. (1942). J. roy. Nav. Med. Serv., 28, 394.

Walter, W. G., and Dovey, V. J. (1944). J. Neurol., Neurosurg., Psychiat., 7, 57. 